\title{
Actividad antimicrobiana del aceite esencial de Clinopodium pulchellum (Kunth) Govaerts "panizara», frente a Pseudomonas aeruginosa y Staphylococcus aureus
}

\section{Antimicrobial activity of the essential oil of Clinopodium pulchellum (Kunth) Govaerts "panizara» against Pseudomonas aeruginosa and Staphylococcus aureus}

Edgar Tapia Manrique*,1, Betsabeth Rivera Castillo², Américo Castro Luna , Martín Cordorhuamán Figueroa ${ }^{4}$, Christian Quispe Yalli ${ }^{5}$, Diego Valdivieso Márquez ${ }^{6}$

\footnotetext{
${ }^{1}$ Facultad de Medicina, Universidad de San Martín de Porres, Perú. 1,2,3,4,6 Instituto de Investigación en Ciencias Farmacéuticas y Recursos Naturales "Juan de Dios Guevara";

Facultad de Farmacia y Bioquímica, Universidad Nacional Mayor de San Marcos, Perú.

${ }^{5}$ Facultad de Ingeniería de Alimentos y Pesquería, Universidad Nacional del Callao, Perú.
}

\section{Resumen}

La investigación presenta como objetivo evaluar la actividad antimicrobiana del aceite esencial de las hojas de Clinopodium pulchellum (Kunth) Govaerts "panizara» in vitro frente a cepas de Staphylococcus aureus subsp. aureus (ATCC ${ }^{\circledR} 6538^{\mathrm{TM}}$ ) y Pseudomonas aeruginosa (ATCC ${ }^{\circ} 9027^{\mathrm{TM}}$ ). $\mathrm{El}$ aceite esencial se obtuvo tratando $5 \mathrm{~kg}$ de hojas, recolectadas en el distrito de Huacaschuque, provincia de Pallasca, región Ancash ubicada a 3100 metros de altitud; mediante un sistema de destilación indirecta con arrastre de vapor de agua, reportándose un rendimiento de $0.58 \%$ v/p. La determinación de la actividad antimicrobiana in vitro, se realizó empleando el método de difusión en agar Mueller-Hinton a concentraciones de 100\%, 75\%, 50\% y 25\%. Los resultados obtenidos demuestran que el aceite esencial de las hojas de panizara, presenta actividad antimicrobiana significativa frente a S.aureus

Este es un artículo Open Access bajo la licencia Creative Commons Atribución-NoComercial-Compartirlgual 4.0

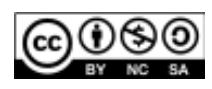


ATCC $® 6538^{\mathrm{TM}}$, pero no presenta actividad antimicrobiana significativa frente a P. aeruginosa ATCC $® 9027^{\mathrm{TM}}$, se utilizó ciprofloxacino y dimetilsulfoxido como control positivo y negativo, respectivamente.

Palabras clave: aceite esencial, Clinopodium pulchellum (Kunth) Govaerts, Staphylococcus aureus, Pseudomonas aeruginosa, destilación, antibacteriana.

\begin{abstract}
The objective of the research was to evaluate the in vitro antimicrobial activity of the essential oil of Clinopodium pulchellum (Kunth) Govaerts "panizara" leaves against Staphylococcus aureus subsp. aureus (ATCC ${ }^{\circ} 6538^{\mathrm{TM}}$ ) and Pseudomonas aeruginosa (ATCC ${ }^{\circledR} 9027^{\mathrm{TM}}$ ). The essential oil was obtained by treating $5 \mathrm{~kg}$ of leaves collected in the district of Huacaschuque, province of Pallasca, Ancash region, at $3100 \mathrm{~m}$ a.s.l, by means of indirect steam distillation, which yielded $0.58 \% \mathrm{v} / \mathrm{w}$. The in vitro antimicrobial activity was determined using the Mueller-Hinton agar diffusion method at concentrations of $100 \%, 75 \%, 50 \%$ and $25 \%$. The results obtained show that the essential oil of the panizara leaves has significant antimicrobial activity against $S$. aureus (ATCC $\AA 6538^{\mathrm{TM}}$ ) but does not have significant antimicrobial activity against $P$. aeruginosa (ATCC ${ }^{\circledR} 9027^{\mathrm{TM}}$ ). Ciprofloxacin and dimethylsulfoxide were used as positive and negative controls, respectively.
\end{abstract}

Keywords: essential oil; Clinopodium pulchellum (Kunth) Govaerts; Staphylococcus aureus; Pseudomonas aeruginosa; distillation; antibacterial

\title{
Introducción
}

Las plantas aromáticas de la familia Lamiaceae son usadas como infusiones y han sido ampliamente estudiadas por la presencia de antioxidantes y por sus propiedades antimicrobianas. Dentro de esta familia se encuentra el género Clinopodium, el cual ha sido objeto de diversas investigaciones en aceites esenciales y en diversos extractos; sin embargo, aún no se desarrollan investigaciones del aceite esencial de la especie vegetal Clinopodium pulchellum (Kunth) Govaerts «panizara»; orientadas a evaluar su actividad antimicrobiana frente a bacterias. 
Además, se sabe que en los últimos años existe una tendencia hacia las incrementadas enfermedades producidas por bacterias ${ }^{(1)}$. Las infecciones bacterianas tienen un gran impacto en la salud pública, estas pueden ocurrir en cualquier sitio, las bacterias se transmiten a los humanos por medio del aire, el agua, los alimentos o los vectores vivos. Los principales modos de transmisión de la infección bacteriana son el contacto y el aire, aunque esta brecha es más estrecha cuando se adicionan factores de riesgos (pacientes inmunocomprometidos, quimioterapia, nutrición parenteral, entre otros). Las medidas preventivas tienen un impacto dramático en la morbilidad y mortalidad. Dichas medidas incluyen tratamiento de agua, inmunización de animales y humanos, medidas de higiene personal y prácticas sexuales más seguras. La resistencia bacteriana a los antibióticos es una preocupación creciente que exige su uso prudente ${ }^{(2)}$.

La bacteria gram positiva como el Staphylococcus aureus, es un microorganismo patógeno colonizador común de la piel humana, pero al superar la barrera cutánea, puede causar una variedad de infecciones piógenas y sistémicas, e infecciones agudas y crónicas, síndromes mediados por toxinas tanto en la atención médica como en la comunidad. Además de su concepción clásica como un microorganismo de acción extracelular el Staphylococcus aureus también ha sido reconocido como patógeno intracelular y esta propiedad potencialmente contribuye a la persistencia bacteriana, como la protección contra los antibióticos y la evasión de las defensas inmunes ${ }^{(3,4)}$.

El género Pseudomonas está constituido por bacterias gramnegativas, específicamente Pseudomonas aeruginosa, que se encuentra ampliamente en la naturaleza, en suelo y agua. Clasificado como un patógeno oportunista, causa enfermedades con poca frecuencia en huéspedes normales, pero es un agente causal de importantes infecciones en pacientes que subyacen en condiciones de inmunocompromiso. Además, el genoma de Pseudomonas aeruginosa es especialmente grande para un procariota, y proporciona una comprensión de los mecanismos metabólicos y patógenos que subyacen al éxito de este patógeno versátil, y se ha convertido en un modelo para comprender la variación genómica microbiana y la evolución en enfermedades crónicas. Pseudomonas aeruginosa tiene pocos requisitos nutritivos y puede adaptarse a condiciones no toleradas por otros organismos ${ }^{(18)}$. 
Clinopodium pulchellum (Kunth) Govaerts, es una planta herbácea, aromática perteneciente a la familia Lamiaceae y es reconocida en el Perú por presentar alrededor de 21 géneros, entre hierbas y arbustos ${ }^{(5)}$. Gran parte de las especies presentes en el Perú se encuentran reportadas en el norte del país, de manera específica en los Andes constituyendo un importante hábitat, comprendido entre los 1500 y $4250 \mathrm{~m}$ de altitud ${ }^{(6)}$. Especie ampliamente distribuida en el norte de país, se le encuentra en laderas abiertas y rocosas, también a orillas y acequias, quebradas arcillosas-rocosas, bordes de carreteras. Terrenos boscosos y arcilloso pedregosos ubicados entre los 2800 y $3500 \mathrm{~m} \mathrm{~s}$. n. m., en los departamentos de Cajamarca, Ancash y La Libertad ${ }^{(7)}$. La planta es conocida popularmente por los pueblos como panizara, limoncillo. Los usos tradicionales son efectivos para combatir los trastornos del sistema digestivo y controla las flatulencias o gases estomacales. Se emplea para prevenir la indigestión y puede ser usada como un efectivo relajante ${ }^{(8),(9)}$.

Las propiedades aromáticas de Clinopodium pulchellum se deben a la presencia de componentes de naturaleza lipofílica, definiéndose como fracciones líquidas y volátiles, generalmente destilables por arrastre con vapor de agua, que contienen las sustancias importantes para las industria cosmética (aromatizantes), alimentaria (saborizantes) y farmacéutica (principios activos).

\section{Materiales y métodos}

Es una investigación experimental, la obtención del aceite esencial y el análisis preliminar se realizó en el Instituto de Ciencias Farmacéuticas y Recursos Naturales «Juan de Dios Guevara» de la Facultad de Farmacia y Bioquímica de la Universidad Nacional Mayor de San Marcos (UNMSM). El análisis fisicoquímico se llevó a cabo en el Laboratorio de Fisicoquímica de la Facultad de Farmacia y Bioquímica de la UNMSM. La determinación de la actividad antimicrobiana se realizó en el laboratorio del Instituto de Química Biológica, Microbiología y Biotecnología «Marco Antonio Garrido Malo» de la Facultad de Farmacia y Bioquímica de la UNMSM. 


\section{Material vegetal y bacteriano}

La recolección de las hojas de panizara se realizó en el distrito de Huacaschuque, provincia de Pallasca, capital Cabana, región Ancash ubicada a 3100 metros de altitud. La clasificación taxonómica se llevó a cabo en el Museo de Historia Natural de la UNMSM. Se trabajó con cepas certificadas de Staphylococcus aureus ATCC 6538 y Pseudomonas aeruginosa ATCC 9027.

\section{Extracción del aceite esencial}

$5 \mathrm{~kg}$ de hojas secas fueron tratadas en un equipo de acero inoxidable y sometidas a destilación por arrastre de vapor de agua. El destilado se separó tomando en cuenta sus propiedades de inmiscibilidad y diferencia de densidades entre el agua y el aceite esencial, utilizando una pera de separación, se deshidrató las impurezas de agua en el aceite esencial con sulfato de sodio anhidro grado reactivo, con posterior filtración y conservación del aceite esencial en un frasco de vidrio de color ámbar bajo refrigeración a una temperatura de $4{ }^{\circ} \mathrm{C}$. El rendimiento se determinó por el método gravimétrico-volumétrico, se obtuvo $0.58 \mathrm{~mL}$ de aceite esencial de panizara.

\section{Análisis preliminar y fisicoquímico}

Se realizó el análisis organoléptico y la solubilidad del aceite esencial utilizando diversos solventes orgánicos. Asimismo, se efectuó el análisis fisicoquímico determinándose las principales constantes físicas: densidad por picnometría, $\mathrm{pH}$ por potenciometría, índice de refracción por refractometría. Se realizaron por triplicado según las técnicas estandarizadas de la Official Methods of Analysis of AOAC INTERNATIONAL, 20 ${ }^{\text {th }}$ Edition (2016). 


\section{Evaluación de la actividad antibacteriana del aceite esencial frente a Staphylococcus aureus y Pseudomonas aeruginosa}

Método de difusión en agar ${ }^{(19)}$

Esta prueba se basa en la inhibición del crecimiento bacteriano, mediante la difusión de las sustancias activas en un medio sólido y se evidencia por la formación de halos de inhibición claros alrededor de las colonias.

\section{Microorganismos}

- Staphylococcus aureus ATCC 6538

- Pseudomonas aeruginosa ATCC 9027

\section{Muestra}

Aceite esencial de las hojas de Clinopodium pulchellum (Kunth) Govaerts panizara en concentraciones de $100 \% ; 75 \% ; 50 \%$ y $25 \%$. Utilizando como diluyente dimetilsulfóxido (DMSO).

\section{Preparación del inóculo}

A partir de colonias puras de los microorganismos Staphylococcus aureus y Pseudomonas aeruginosa, se tomó una cierta cantidad de colonias y se diluyó en dos tubos de ensayo conteniendo $10 \mathrm{~mL}$ de suero fisiológico estéril (cloruro de sodio $0.9 \%$ ), de tal manera que la solución resultante tuvo una turbidez correspondiente al tubo $\mathrm{N}^{\circ} 1$ de la escala de McFarland (escala turbidimétrica que consiste en una serie de tubos con turbidez creciente que permite hallar la concentración aproximada de una solución bacteriana) que corresponde a una concentración de $3 \times 10^{(8)} \mathrm{ufc} / \mathrm{mL}$. A partir de esta última solución se realizó una dilución de 1 en 3; para ello, de esta solución preparada se tomó $3 \mathrm{~mL}$ y se diluyó a un volumen total de $9 \mathrm{~mL}$ con suero fisiológico en un tubo con tapa rosca, todos los materiales usados debieron ser estériles, así como el área de trabajo. La solución resultante tuvo una concentración de $1 \times 10^{(8)} \mathrm{ufc} / \mathrm{mL}$. 


\section{Preparación e inoculación de las placas}

Se preparó $1000 \mathrm{~mL}$ de agar Mueller Hinton para la fase analítica en un frasco de vidrio de acuerdo a las instrucciones del fabricante (34 gramos para 1 litro de agua destilada). Se autoclavó el agar a $121^{\circ} \mathrm{C}$ y $15 \mathrm{lb} / \mathrm{pg} 2$ durante 15 minutos. Inmediatamente después de autoclavar se llevó a baño maría a $45-50{ }^{\circ} \mathrm{C}$. Una vez temperado se vertió el preparado fresco y tibio a placas Petri de vidrio estériles, para dar un fondo uniforme de aproximadamente $4 \mathrm{~mm}$, esto corresponde a 25 - $30 \mathrm{ml}$ para placas de 90 $\mathrm{mm}$ de diámetro. El agar ya plaqueado se dejó solidificar a temperatura ambiente. El pH de cada lote de agar Mueller Hinton tuvo un $\mathrm{pH}$ entre 7,0-7,6. Esta medición se realizó sumergiendo el bulbo del electrodo del potenciómetro en el agar antes de autoclavar.

Se agregó 100 uL del inóculo bacteriano preparado de Staphylococcus aureus y Pseudomonas aeruginosa $\left(1 \times 10^{(8)} \mathrm{ufc} / \mathrm{mL}\right)$ a 2 placas con agar Mueller Hinton, por cada cepa y con la ayuda de una espátula de Drigalsky se esparció el inóculo por todas las placas de tal manera que se obtuvo un crecimiento homogéneo, para lo cual se deslizó el asa en la placa en forma paralela y bien compacta abarcando toda la superficie de la misma. Luego se repitió el procedimiento rotando la placa $60^{\circ}$ en dos oportunidades más; se dejó secar de 3 a 5 minutos antes de hacer los pocillos.

\section{Formación de los pocillos}

Se esterilizó el sacabocado con alcohol y se flameó en el mechero, luego con mucho cuidado se hicieron los pocillos, tres por cada placa. Los pocillos debieron estar a más de $15 \mathrm{~mm}$ del borde de la placa y se distribuyeron de tal manera que no haya superposición de los halos de inhibición.

\section{Sembrado de las muestras y controles}

Se usó dos placas para cada concentración del 25\%, 50\%, 75\% y 100\%, una placa por cada cepa. Cada dilución se sembró por triplicado añadiendo 40 $\mathrm{uL}$ en cada pocillo. Como control negativo o muestra blanco (DMSO). En una placa por cada cepa y se sembró $40 \mathrm{uL}$ por triplicado. Como control positivo se usó Ciprofloxacino a $40 \mathrm{ug} / \mathrm{mL}$. En una placa por cada cepa y se sembró $40 \mathrm{uL}$ por triplicado. 


\section{Incubación}

Las 4 placas de las muestras y los controles se llevaron a una incubadora a $37^{\circ} \mathrm{C}$ durante 24 horas.

\section{Lectura e interpretación de los resultados}

Después de 24 horas de incubación, cada placa fue examinada. Las zonas de inhibición resultantes deben ser uniformemente circulares en una capa homogénea de crecimiento bacteriano. Los diámetros de la zona de inhibición completa se midieron en milímetros pasando por el centro de cada pocillo. La medición se realizó por triplicado para cada pocillo con un vernier digital que mide hasta centésima de milímetro. Los valores de las mediciones por triplicado se promediaron y se redondearon para reportarlo como un número natural. Se considera que tiene una actividad antibacteriana significativa a un halo de inhibición mayor a $18 \mathrm{~mm}$.

\section{Análisis estadístico}

Minitab para Windows (Minitab 18, State College, Pennsylvania, USA) fue usado para el análisis estadístico de los datos. Se verificó la adecuación de los datos y que los errores experimentales siguen una distribución normal e independiente. Los datos numéricos se analizaron mediante un análisis de varianza de un solo factor (ANOVA) y evaluación del p-Valor, para luego realizar la comparación de las medias de la diferente actividad antimicrobiana mediante la prueba Tukey. Finalmente, para verificar la significancia del efecto antimicrobiano del aceite esencial frente a los microorganismos en estudio, se realizó una prueba unilateral de hipótesis, donde se contrastó con el diámetro de halo de inhibición de referencia (18 $\mathrm{mm}$ ). Todas las pruebas estadísticas se realizaron a un nivel de significancia del $5 \%$.

\section{Resultados}

\section{Rendimiento del aceite esencial}

El rendimiento se determinó por el método gravimétrico-volumétrico se obtuvo $0.58 \mathrm{~mL} \% \mathrm{v} / \mathrm{p}$ de aceite esencial de panizara. 


\section{Análisis fisicoquímico}

- Análisis organoléptico: líquido oleoso, ligeramente amarillo, aromático, agradable y altamente volátil.

- Solubilidad: insoluble en agua, ligeramente soluble en metanol, soluble en dimetilsulfóxido, etanol, n-hexano y éter etílico.

- Constantes físicas: densidad $\left(21^{\circ} \mathrm{C}\right)$ : 0.978; $\mathrm{pH}\left(21^{\circ} \mathrm{C}\right)$ : 5.60 ; índice de refracción $\left(21^{\circ} \mathrm{C}\right): 1.475$

\section{Análisis microbiológico}

Los resultados obtenidos de la actividad antimicrobiana del aceite esencial de panizara frente a Staphylococcus aureus ATCC 6538 se presentan en la Tabla 1.

\section{Tabla 1}

Resultados de la actividad antimicrobiana del aceite esencial de Clinopodium pulchellum (Kunth) Govaerts «panizara» frente a Staphylococcus aureus ATCC 6538 empleando el método de difusión en agar

\begin{tabular}{lcc}
\hline \multicolumn{1}{c}{ Muestra } & Concentración & $\begin{array}{c}\text { Staphylococcus aureus } \\
\text { (promedio de los diámetros } \\
\text { del halo de inhibición en mm) }\end{array}$ \\
\hline Aceite esencial & $100 \%$ & 35 \\
de Panizara & $75 \%$ & 35 \\
Control positivo & $50 \%$ & 34 \\
\hline Control negativo & $25 \%$ & 30 \\
\hline
\end{tabular}

Leyenda:

- DMSO: Dimetilsulfóxido

- Actividad antibacteriana significativa (>18 mm) 

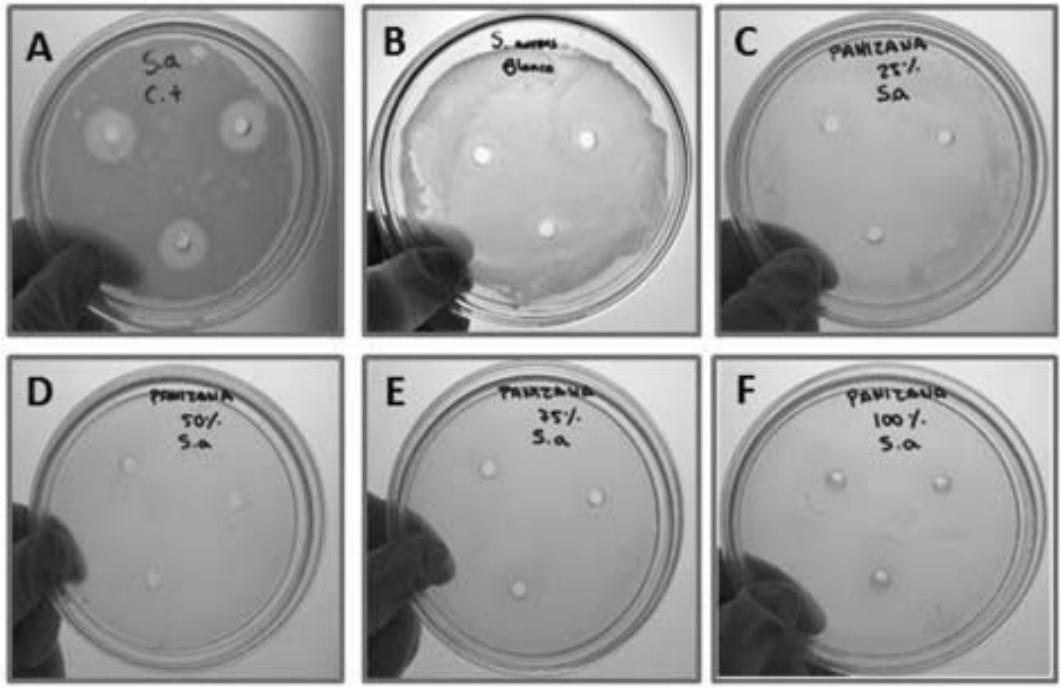

Figura 1. Formación de halo de inhibición frente a Staphylococcus aureus en control positivo (A), control negativo (B) y en concentraciones de $25 \%$ (C), 50\% (D), $75 \%$ (E) y $100 \%(F)$.

\section{Tabla 2}

Resultados de la actividad antimicrobiana del aceite esencial de Clinopodium pulchellum (Kunth) Govaerts «panizara» frente a Pseudomonas aeruginosa ATCC 9027 empleando el método de difusión en agar

\begin{tabular}{lcc}
\hline \multicolumn{1}{c}{ Muestra } & Concentración & $\begin{array}{c}\text { Staphylococcus aureus } \\
\text { (promedio de los diámetros } \\
\text { del halo de inhibición en mm) }\end{array}$ \\
\hline Aceite esencial & $100 \%$ & 10 \\
de panizara & $75 \%$ & 9 \\
\hline Control positivo & $50 \%$ & 11 \\
\hline Control negativo & $25 \%$ & 10 \\
\hline
\end{tabular}

Leyenda:

- DMSO: Dimetilsulfóxido

- Actividad antibacteriana significativa (> $18 \mathrm{~mm})$ 

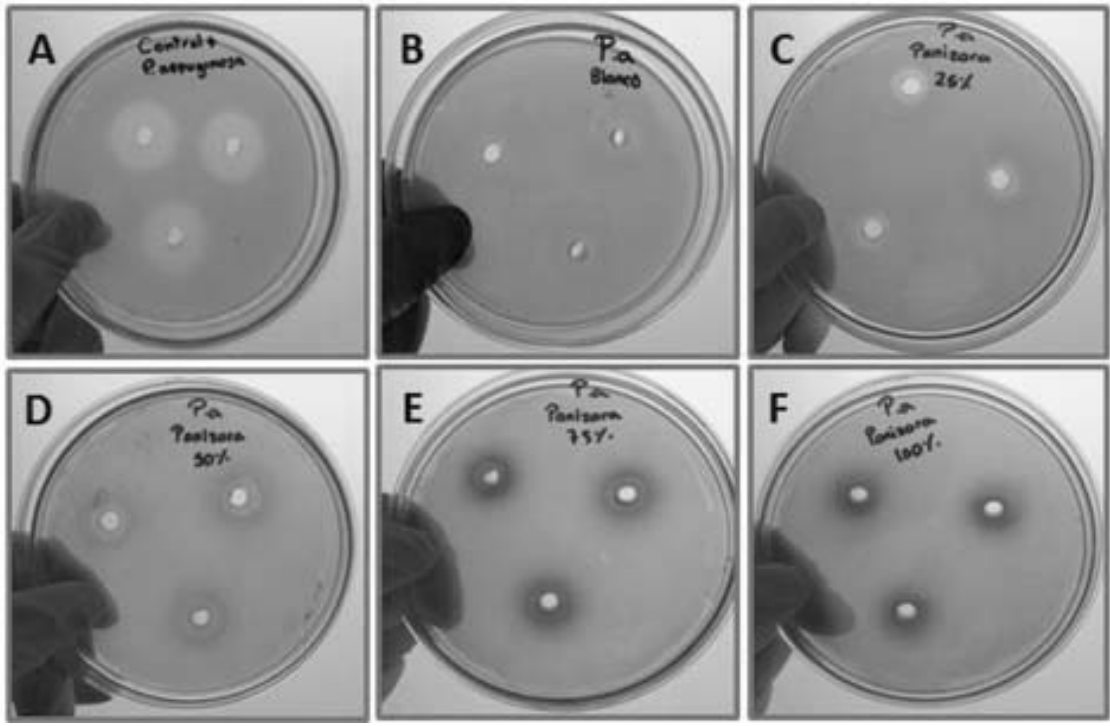

Figura 2. Formación de halo de inhibición frente a Pseudomonas aeruginosa en control positivo (A), control negativo (B) y en concentraciones de $25 \%$ (C), 50\% (D), 75\% (E) y $100 \%(F)$.

\section{Análisis estadístico}

En el Gráfico 1 se observa como los residuales mostraron una independencia y variabilidad constante, así como una distribución normal para Pseudomonas aeruginosa (a) y Staphylococcus aureus (b) con p-valor de 0.097 y 0.133 , respectivamente. Esto garantizó realizar el análisis de varianza de los tratamientos en estudio.

En el Cuadro 1 se muestra el ANOVA, donde el aceite esencial de panizara tuvo un efecto significativo sobre la inhibición de la Pseudomonas aeruginosa $(p<.05)$ y Staphylococcus aureus $(p<.05)$, por lo tanto, hubo diferencias entre las medias de las concentraciones de aceite esencial de panizara (\%) sobre la actividad antimicrobiana. En la Figura 1 también se muestra que el 69\% de la variación de la formación del halo de inhibición frente a la Pseudomonas aeruginosa está explicada por el efecto del aceite esencial de panizara y $72.3 \%$ para el Staphylococcus aureus. 
En el Grafico 2 (a) se muestra que con el 50\% de aceite esencial de Panizara se consigue un mayor efecto de inhibición sobre la Pseudomonas aeruginosa con $11.44 \pm 0.88 \mathrm{~mm}$, mientras que con el $75 \%$ de aceite esencial se obtuvo el menor efecto de inhibición con $8.78 \pm 0.44 \mathrm{~mm}$. En el Grafico 2 (b) se muestra que con el $100 \%$ de aceite esencial de panizara se consigue un mayor efecto de inhibición sobre la Staphylococcus aureus con $35.44 \pm 0.73$ $\mathrm{mm}$, mientras que con el $25 \%$ de aceite esencial se obtuvo el menor efecto de inhibición con $29.78 \pm 2.05 \mathrm{~mm}$. También se observa en el Gráfico 2 (a), que no hubo una diferencia significativa entre las concentraciones de $75 \%$ y $100 \%$ para la Pseudomonas aeruginos; mientras que en el Gráfico 2 (b), para el Staphylococcus aureus, no hubo una diferencia significativa para las concentraciones de 50\%,75\% y 100\% de aceite esencial de panizara, por lo tanto, se podría afirmar que estos tres porcentajes brindaron el mismo resultado, estadísticamente, ya que comparten el mismo intervalo de confianza.

En el Cuadro 2 se presenta el resultado de la prueba de hipótesis unilateral para verificar la eficacia del aceite esencial como inhibidor de la Pseudomonas aeruginosa y Staphylococcus aureus. En el Cuadro 2 (a) se observa que el p-valor fue menor a 0.05 , se concluye que el halo de inhibición media de las concentraciones del aceite esencial de panizara fue menor a $18 \mathrm{~mm}$; por lo tanto, el aceite esencial de panizara no presenta un efecto antimicrobiano significativo frente a Pseudomonas aeruginosa. En el Cuadro 2 (b) se observa que el p-valor fue menor a .05, se concluye que el halo de inhibición media de las concentraciones del aceite esencial de panizara fue mayor a $18 \mathrm{~mm}$; por lo tanto, el aceite esencial de Panizara presenta un efecto antimicrobiano significativo frente a Staphylococcus aureus. 
(a)

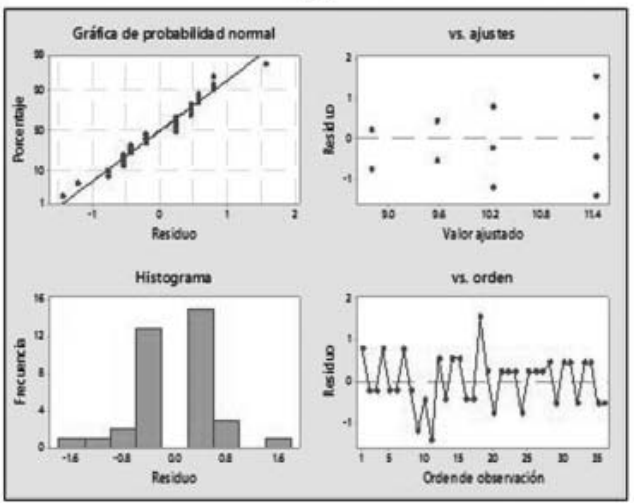

(b)

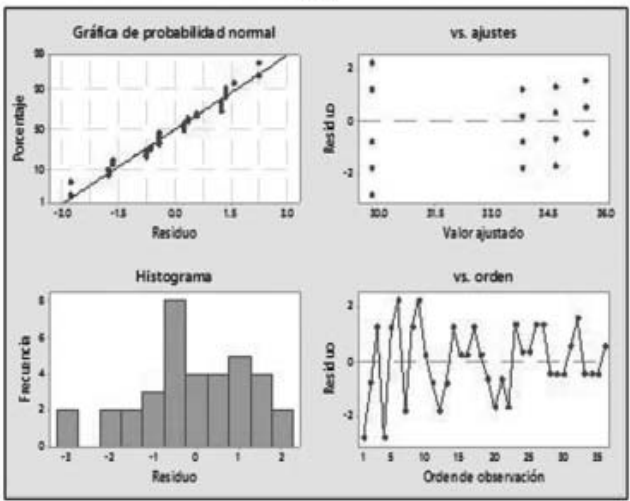

Gráfico 1. Evaluación de los residuales de las observaciones de la formación de halo de inhibición frente a Pseudomonas aeruginosa (a) y Staphylococcus aureus (b).

Cuadro 1. ANOVA de la formación de halo de inhibición frente a Pseudomonas aeruginosa (a) y Staphylococcus aureus (b).

(a)

\section{Análisis de Varianza}

\begin{tabular}{lrrrrr} 
Fuente & GL & SC Ajust. & MC Ajust. & Valor F & Valor $p$ \\
\hline Aceite esencial de Panizara (\%) & 3 & 34.44 & 11.4815 & 27.10 & 0.000 \\
Error & 32 & 13.56 & 0.4236 & & \\
Total & 35 & 48.00 & & &
\end{tabular}

\section{Resumen del modelo}

R-cuad. R-cuad.

S R-cuad. (ajustado) (pred)

\begin{tabular}{llll}
\hline 0.650854 & $71.76 \%$ & $69.11 \%$ & $64.26 \%$
\end{tabular}

\section{Análisis de Varianza}

\section{(b)}

\begin{tabular}{lrrrrr} 
Fuente & GL & SC Ajust. & MC Ajust. & Valor $F$ & Valor $p$ \\
\hline Aceite esencial de Panizara (\%) & 3 & 171.42 & 57.139 & 31.89 & 0.000 \\
Error & 32 & 57.33 & 1.792 & & \\
Total & 35 & 228.75 & & &
\end{tabular}

\section{Resumen del modelo}

R-cuad. R-cuad.

\begin{tabular}{rrrr} 
S & R-cuad. & (ajustado) & (pred) \\
\hline 53 & $74.94 \%$ & $72.59 \%$ & $68.28 \%$
\end{tabular}


(a)

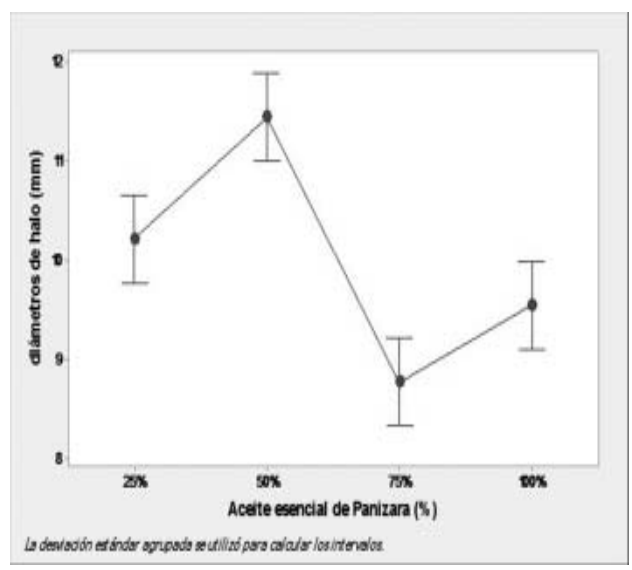

(b)

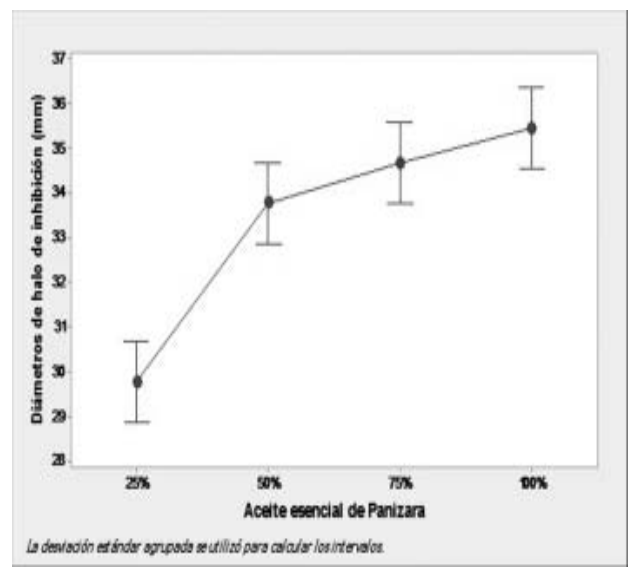

Gráfico 2. Gráfico de intervalos de la formación de halo de inhibición del Pseudomonas aeruginosa (a) y Staphylococcus aureus (b) con respecto a la cantidad de aceite esencial de Panizara al 95\% de confianza.

Cuadro 2. Prueba de hipótesis unilateral para verificar la eficacia del aceite esencial frente a Pseudomonas aeruginosa.

(a)

\section{Estadísticas descriptivas}

\begin{tabular}{rrrrr} 
& & & $\begin{array}{r}\text { Error } \\
\text { estándar } \\
\text { de la }\end{array}$ & $\begin{array}{r}\text { Limite } \\
\text { superior } \\
\text { de } 95 \% \\
\text { p }\end{array}$ \\
& Media & Desv.Est. & media & para $\mu$ \\
\hline 36 & 10.000 & 1.171 & 0.195 & 10.330
\end{tabular}

$\mu$ : media de diómetros de holo (mm)

\section{Prueba}

Hipótesis nula $H_{0}: \mu=18$

Hipótesis alterna $H_{2}: \mu<18$

\begin{tabular}{lr} 
Valor T & Valor $p$ \\
\hline-40.99 & 0.000
\end{tabular}

(b)

\section{Estadísticas descriptivas}

\begin{tabular}{rrrrr}
$N$ & Media & Desv.Est. & $\begin{array}{r}\text { Error } \\
\text { estándar } \\
\text { de la } \\
\text { media }\end{array}$ & $\begin{array}{r}\text { Limite } \\
\text { inferior } \\
\text { de }\end{array}$ \\
\hline 36 & 33.417 & 2.557 & 0.426 & 32.697 \\
\hline
\end{tabular}

\section{Prueba}

\begin{tabular}{ll} 
Hipótesis nula & $H_{0}: \mu=18$ \\
Hipótesis alterna & $H_{2}: \mu>18$ \\
Valor T Valor $p$ & \\
\hline 36.180 .000 &
\end{tabular}




\section{Discusión}

A partir de $5 \mathrm{~kg}$ de hojas frescas de Clinopodium pulchellum (Kunth) Govaerts «panizara», proveniente de la región Ancash, se obtuvo un rendimiento del $0.58 \% \mathrm{v} / \mathrm{p}$; reportó un rendimiento del aceite esencial de panizara del $1 \%$ $\mathrm{v} / \mathrm{p}^{(10)}$, esta diferencia puede deberse a diversos factores, como ecológicos, climáticos y edafológicas que influyen en el rendimiento y en la calidad del aceite esencial ${ }^{(11)}$.

Se enfatiza que el rendimiento del aceite esencial es una característica importante desde el punto de vista económico y de disposición del recurso vegetal en el proceso de su obtención, puede variar desde $0.01 \%$ hasta el $4 \%$; al comparar con nuestro resultado podemos indicar que el rendimiento obtenido es óptimo ya que se encuentra dentro del rango ${ }^{(12)}$. Los datos obtenidos en el análisis preliminar y las constantes fisicoquímicas del aceite esencial de panizara como la solubilidad, densidad, índice de refracción y el $\mathrm{pH}$, indican que presentan características fisicoquímicas propias de los aceites esenciales. ${ }^{(13)}$

En la investigación de la actividad antimicrobiana, por los resultados obtenidos (Tabla 1), se ha demostrado que el aceite esencial de Clinopodium pulchellum (Kunth) Govaerts «panizara» posee actividad significativa frente a Staphylococcus aureus en las concentraciones de 25\%,50\%, 75\% y 100\%. Esta actividad podría atribuirse a la presencia de ciertos terpenos presentes en su composición química ${ }^{(4)}$.

Existen varios estudios evidenciando que los componentes químicos denominados terpenoides, son los principales constituyentes mayoritarios de la actividad antimicrobiana de los aceites esenciales, siguiendo en orden de actividad individual los derivados de los terpenos que contengan fenoles y alcoholes, seguido por los aldehídos y cetónicos ${ }^{(14)}$. Se refiere, que el aceite esencial de Lemon grass posee cantidades considerables de $\alpha$-citral, $\beta$-citral, citronellol, citronelal, linalool y geraniol, demostrando poseer actividad antimicrobiana ante Escherichia coli, Bacillus subtilis y Staphylococcus aureus.

La actividad antimicrobiana del limoneno y gamma-terpineno, pueden atribuirse a que producen efectos en la integridad de membrana de las 
bacterias y hongos en consecuencia inhiben la respiración y afectan el proceso de transporte de iones ${ }^{(15)}$. Una investigación fitoquímica y antimicrobiana demostró la presencia de terpenoides (esquizonepetosido y esquizonepedosido C), del aceite esencial Clinopodium pulchellum (Kunth), analizado por GC-MS y GC-FID ${ }^{(16),(17) .}$

\section{Conclusiones}

El aceite esencial de las hojas de Clinopodium pulchellum (Kunth) Govaerts «panizara» posee actividad antibacteriana in vitro significativa frente a Staphylococcus aureus.

El aceite esencial de las hojas de Clinopodium pulchellum (Kunth) Govaerts «panizara» no posee actividad antibacteriana in vitro significativa frente a Pseudomonas aeruginosa.

\section{Referencias}

1. Navarro VM, Gonzalez A, Fuentes M, Aviles M, Rios MY, Zepeda G, Rojas MG. Antifungal activites of nine traditional Mexican medicinal plants. J. Ethnopharmacol. 2003;87(1):85-8.

2. López S N, Castelli M V, Zacchino SA, Domínguez JN, Lobo G, Charris-Charris J, Cortes J C, Ribas JC, Devia C, Rodríguez AM, Enriz RD. In vitro antifungal evaluation and structure-activity relationships of a new series of chalcone derivatives and synthetic analogues, with inhibitory properties against polymers of the fungal cell wall. Bioorg Med Chem. 2001;9(8):1999-2013.

3. Fajardo LM, Navarro RF. Caracterización del aceite esencial de la especie Peperomia subspathulata (Piperácea) y evaluación de su capacidad como agente antimicrobiano. 2017. Recuperado de http:// repository.udca.edu.co:8080/jspui/handle/11158/7168.

4. Tapia ER. Composición química, actividad antioxidante y anticandida albicans del aceite esencial de Clinopodium pulchellum (Kunth) Govaerts «panizara». Universidad Nacional Mayor San Marcos [Internet]. 2018. recuperado de http://cybertesis.unmsm.edu.pe/handle/cybertesis/7557

5. Rodríguez M. Lamiaceae endémicas del Perú. Revista peruana de Biología. 2006;13(2):371-79.

6. Sagástegui A, Rodríguez E. Una nueva especie de Salvia (Lamiaceae) del Norte del Perú. Revista peruana de Biología. 2012; 13(2): 139-42.

7. Tapia E y col. Actividad antioxidante del aceite esencial de Clinopodium pulchellum (Kunt) Govaerts «panizara», Agora Rev Cient. 2017;4(2): 1-6.

8. Instituto Cuencas. Conocimientos tradicionales de plantas medicinales en Cajamarca, Perú-2012.

9. Pérez, F. Composición química y actividad antibacteriana del aceite esencial de las hojas frescas de Eryngium foetidum L. «siuca culantro», Tesis Químico Farmacéutico. Facultad de Farmacia y Bioquímica. UNMSM. 2012. 
10. Carhuapoma M, López S, Veliz F, Inostrosa L, Yuli R, Carlos N. Composición química, actividad antioxidante y toxicidad aguda del aceite esencial de Saturaje pulchella «panizara». Theorema UNMSM. 2014;1(1):5763.

11. Crop \& Food Research. Essential oils and their production. New Zealand, Institute for Crop \& Food Research Institute 2001; (39):1-11. Recuperado de http://www.crop:cri.nz/home/productsservices/publications/ broadsheets/039essentialoils.pd

12. Jaramillo E, Stashenko E, Martinez J. Composición química volátil de Satureja brownei (Sw.) Briq Colombiana y determinación de su actividad antioxidante. Revista cubana de plantas medicinales. 2010; 15(1):14-23.

13. Domínguez, X. Métodos de Investigación Fitoquímica. (3ª edición). Edit. Limusa, S.A.. México. 1985; 1(1): 229-238.

14. Shane, G. Aspects of antimicrobial activity of terpenoids and the relationship to their molecular structure. Phisic Bulletin. 1979;(1):30; 262.

15. Martins R, Salgueiro M, Goncalves R, Vila F, Tomi T, Casanova J. Antimicrobial activity and chemical composition of the bark oil 89 of Croton stellulifer, an endemic species from S Tome e Pricipe, Planta Med. 2000;66(1):647-650.

16. Gianluca G, Malagon O, Morocho V, Negri R, Solveig T, Guglielminettill M., Vidaril G, Finzil P. Phytochemical researches and antimicrobial activity of Clinopodium nubigenum Kunth (Kuntze) raw extracts 2011;21(5):850-855.

17. Gilardoni G, Malagon 0 y col. Phytochemical researches and antimicrobial activity of Clinopodium nubigenum Kunth (Kuntze) raw extracts. Rev. bras. farmacogn. 2011;21(5):850-855. Recuperado de http:/l dx.doi.org/10.1590/S0102-695X2011005000139.

18. Lebeque $\mathrm{Y}$, Morris $\mathrm{H}$, Calas $\mathrm{N}$. Infecciones nocosomiales: incidencia de la Pseudomonas aeruginosa Rev cubana med. 2006;45(1):1-4. Recuperado de http://scielo.sld.cu/scielo.php?script=sci_arttext\&pid=S003475232006000100005

19. Rojas R, Bustamante B, Bauer J, Fernández I, Albán J, Lock O. Antimicrobial activity of selected Peruvian medicinal plants. J. Ethnopharmacol. 2003;88(2-3):199-204. 